\title{
Relationship between Students' Metacognitive Strategy and Self-Efficacy in Speaking
}

\author{
Adam \\ English Education Department \\ University of Riau Kepulauan \\ adamedumy@gmail.com
}

\begin{abstract}
The main purpose of this research is to investigate the relationship between students' metacognitive strategy and their self-efficicacy in speaking skills. Besides, this study also investigates the overall level of students' use of metacognitive strategy and the level of their self-efficacy in speaking skills. The sample of this research was the eighth grade students of SMP 26 Batam in the academic year 2016/2017. The data were collected using questionnaires and were calculated using a Likert Scale. There were three findings of this research. First, The overall level of students' metacognitive strategy in speaking skills was 3.3. Second, the overall level of students' self-efficacy in speaking skills was 3.27. Third, there was a positive correlation between students' metacognitive strategy and their self-efficicacy in speaking skills which was indicated by the correlation coefficient of 0.54 . There is a significant correlation between students' metacognitive strategy and their self-efficacy in speaking skills as indicated by the correlation coeficient of 0.54 . There is a positive direction of the correlation as indicated by the correlation coeficient above zero and near to 1 . The students' overall metacognitive strategy use in speaking skills is a medium level as indicated by the mean score of 3.3 The students' overall self-efficacy in their speaking skills is a medium level as indicated by the mean score of 3.27.
\end{abstract}

Keywords : metacognitive, self-efficacy, speaking skills

\section{INTRODUCTION}

Speaking skill is one of the most crucial skills to master in order to be able to communicate interactively. Mastering the speaking skill will give an easy access to a real life use of language. It is, therefore, emphasized to the students to have a good mastery of speaking skill. The studies about oral skills have begun from the twentieth century. The studies continue until the present days to find everything that might be helpful for language learners in their speaking skills. Linguists put more emphasis on speaking than writing, reading and listening as it relates to social interaction more than the three other skills - listening, reading, and writing. 
Speaking is a productive skill that needs active language components - grammar, vocabulary, pronunciation - in order to be able to produce it. This has made it a difficult skill to master. As language learners, speaking skills are even more difficult than other skills since students have minimum exposure to the target language environment and culture. Learning and exposure are two things that have different difficulty level in speaking mastery. Learning is a conscious effort of students that need a lot of tedious work. As oppose to learning, mastering speaking through exposure is quiet a natural and easy one. However, in a school setting, students are not brought to an exposure, although there is little that demands students to use their maximal effort through learning consciously in a classroom instruction setting. This reason has made speaking receives more attention in teaching and learning than other language skills. Responding to this, many have been done by experts to help students with their speaking skill. Various teaching methods and approaches, and learning strategies have been researched to contribute to the teaching and learning speaking skills.

Despite many research conducted regarding speaking skills, still, it is not an easy skill to master by students and teaching it is no easy task for teachers. Most students are afraid of making mistakes and feel nervous when they are speaking. One of the main causes of these problems might be that students do not have a high motivation and self-efficacy in their speaking skill. They are not confident with their ability to speak in English. The problem in self-efficacy to do something might get students stuck in speaking. This can cause their cognitive processes with their active English components they have.

This often the problem that students lose their active English components such as grammar, vocabulary and pronunciation that have been active in their cognitive processing when they speak; they are not able to productively work with them when they interact with their interlocutors spontaneously in speaking without any good and conscious preparation. Their lack of confidence makes their active language components become perceptive language components that they need a prompt to recognize them back even with good cognitive strategies.

On the other hand, there are also some students that can speak confidently despite their bad cognitive strategies. They look very manageable in their speaking although they have a bad overall English skill. They can compensate themselves when they interact in speaking. It is assumed that they have a good metacognitive strategy they employ when they have to practice their speaking skill with each other. They are aware of what they are going to do and 
what they do when they speak. Not only are they aware of the preparation and their self control in speaking but also their self evaluation each time after practicing their speaking skills. They seem to believe that they can do better in speaking although only with little English skills.

Regarding this, there is a need to know why students feel so nervous and lack of confidence when speaking. There may be a relationship between their metacognitive strategy and their self-efficacy in speaking skill. Therefore, the researcher would like to research on this problem at great eight students of SMP N 26 Batam entitled "investigating the relationship between students' metacognitive strategy and self-efficacy in their speaking skill.

\section{The research questions of this research are:}

1. Is there any relation between students' metacognitive strategies and their self-efficacy in speaking skill?

2. How is the average metacognitive strategy employed by students in their speaking process?

3. What is the average level of students' self-efficacy in their speaking process?

\section{The purposes of the research are:}

1. To find out if there is any relation between students' metacognitive strategies and their self-efficacy in speaking skill.

2. To find out students' average metacognitive stratgy in speaking process

3. To find out the average level of students' self-efficacy in speaking process.

\section{Speaking}

Brown (2010: 184) defined speaking as one of the four basic skills in English is included into productive skills as it involves active language components in the production. Speaking is defined as social activitiess that involve communication among people having conversation with each other. Brown (2010:185) divides five basic types of speaking:

\section{Imitative speaking}

Imitative speaking is the ability to simply parrot back or imitate a word or phrase or possibly a sentence. Although this is a purely phonetic level of oral production, a number of prosodic, lexical and grammatical properties of language may be included in the 
performance criteria. This types of speaking involves more on pronunciation and without making any inference about storage of a prompt. In other words, this type of speaking is the ability to imitate English phonetics.

\section{Intensive speaking}

Intensive speaking is the type of speaking which relates to the ability to the production of short stretches of oral language designed to demonstrate competence in a narrow band of grammatical, phrasal, lexical or phonological relationships. The speakers are aware of semantic properties to be able to respond.

\section{Responsive speaking}

Responsive speaking is the ability to speak in a very short conversation, standard greeting and small talk, simple requests and comments and the like. A stimulus is almost always a spoken prompt with only one or two follow-up questions or retorts.

\section{Interactive speaking}

Interactive speaking is different from responsive speaking in length and complexity of the interaction, which sometimes includes multiple exchanges and/or multiple participants. Interactive speaking can be divided into two parts:

a. Transactional language, which has the purpose of exchanging specific information.

b. Interpersonal exchanges, which have the purpose of maintaining social relationships.

\section{Extensive speaking}

Extensive speaking includes speeches, oral presentations and storytelling, during which the opportunity for oral interaction from listeners is either highly limited or ruled out altogether. Language style is frequently more deliberative and formal for extensive tasks.

According to Griffith (2008:99) metacognitive is defined as the ability to reflect on what is known, and does not simply involve thinking back on an event, describing what happened, and the feelings associated with it. It results in critical but healthy reflection and evaluation of thinking that my result in making specific changes in how learning is managed. 


\section{METHODOLOGY}

The design of this research is a correlational research. According to Arikunto (2006:270) A correlational research aims to investigate the relationship between two or more variables. This research attempted to investigate between the two variables of the research namely metacognitive strategy and self-efficacy. It was to see if there was any positive strong correlation between students metacognitive strategy they employ when speaking and their selfefficacy.

This research used total sampling. Since the total number of the students was 32 students, the researcher took the whole number of the students in order to make a good and strong generalization of the finding of the research to the seventh grade students of SMP N 26 Batam in the academic year 2016/2017.

\section{RESULTS}

The correlation coeficient shows a positive correlation direction as 0.54 is a positive correlation which is greater than 0 and near to 1 . After finding the correlation coeficient, a hypothesis testing is needed to see if $\mathrm{H}_{1}$ is accpeted and $\mathrm{H}_{0}$ is rejected. To do this the correlation coeficient as $r_{\text {computed }}$ will need to be referred to product moment criticcal value as $r_{\text {table }}$ for the degree of alpha $=0.05(\alpha=0.05)$. The higher the sum the mean score of their metacognitive strategy the higher their level of metacognitive strategy employment in their speaking skills as it is determined by Likert Scale. The scale ranges from always with the value of 5 , often $=4$, sometimes $=3$, rarely $=2$ to never $=1$.

The total score of students metacognitive strategy in speaking skill is 106.4 with the average score of 3.3. The 3.3 average score indicates that the students' use of metacognitive strategy in their speaking skill is medium. This is based on the Likert Scale value criteria. There was one student scored very high with 4.6 out of 5.00 or about $3.1 \%$ out of $100 \%$; 14 students were medium with the scores range from 2.1 ( 1 student : 3.1\%), 2.2 (1 student :3.1\%), 2.3 (2 student : 6.2\%), 2.8 (2 students : 6.2\%), 2.9 (2 students : 6.2\%) to 3.4 (6 students : $18.8 \%$ ); and 17 students scored high with the scores range from 3.5 (6 students : 18.8\%), 3.6 (5 students : $15.6 \%$ ), 3.7 (1 student : $3.1 \%$ ), to 3.8 (1 student : $3.1 \%$ ). There was only one 
student who got very high degree of self-efficacy in speaking skill with the score of 4.6 and the percentage of 3.1 from the total number of 27 students. 24 students got medium or about $75 \%$ from the total number of 32 studetns with the scores range from 2.2 to 3.4 . They were 2.2 (1 students : 3.1), 2.3(1 student : 3.1\%), 2.4 (1 student : 3.1\%), 2.7 (1 student : 3.1\%), 2.8 (2 students : 6.2\%), 2.9 (1 student : 3.1\%), 3.1 (1 student : 3.1\%), 3.2 (3 students : 9.4\%), 3.3 (5 students : 15.6\%), and 3.4 (8 students : 25\%). The rest 7 studetns got high or about $21.8 \%$ from the total number of the students with the scores range from 3.6, to 3.9. They were 5 students got 3.6 or about $15.6 \%$ from the total of the students, 1 student got 3.7 or about $3.1 \%$, and 1 student got 3.9 or about $3.1 \%$ from the total number of the students. The overall level of students' self-efficacy in speaking was indicated by the mean score of $\mathbf{3 . 2 5}$. This means that they are in a medium level of self-efficacy in speaking skills. This was referred to the Likert Scale.

\section{DISCUSSION}

From the calculation of the correlation coefience and the hypothesis testing, it is clear that there is a significant correlation between students' metacognitive strategy and their selfefficacy in their speaking skill. This further means that students with a good employment of metacognitive strategy have at least the connection with their self-efficacy in speaking although a correlation does not mean the effect of one variable to other variable. In other words, the students understanding what they know, what they should do, what they are doing, and what they did (implication of a metacognitive strategy) tend to have a good and higher self efficacy in their speaking skill. They feel confident in speaking; believe thay can speak; and believe they can be successful in speaking (self-effiacy) with their good preparation, action and evaluaton (metocognitive strategy) in promoting their speaking. On the other hand, the students without any good metacognitive strategy will then to have a low degree of self efficacy in speaking. This clearly explains the correlation between the two variables of the research. From the finding, the average use of students' metacognitive strategy was a medium level. This was indicated by the mean score of 3.3. The interpretation is that students are not very good at their metacognitive stragey employment in promoting their own speaking skils. In a non-technical term, it implies that they are not very good language learners where they can only make an average preparation, action and evaluation. In short, they do not effectively know what they know, what they will do, what they're doing and what they did in speaking activities. The third 
finding shows that the overall level of the students' self-efficacy was medium as indicated by the mean score of 3.27. The interpretion is that they feel a normal belief of their self in speaking, not to eager, not so much confident and do not really feel that they will succeed their speaking skills.

After analysing the data to find out the three research questions about the corrleation between students' metacognitive strategy and self-efficacy of as the finding of the research, the research has finally come to conclusion:

1. There is a significant correlation between students' metacognitive strategy and their self-efficacy in speaking skills as indicated by the correlation coeficient of 0.54

2. There is a positive direction of the correlation as indicated by the correlation coeficient above zero and near to 1 .

3. The students' overall metacognitive strategy use in speaking skills is a medium level as indicated by the mean score of 3.3

4. The students' overall self-efficacy in their speaking skills is a medium level as indicated by the mean score of 3.27

\section{REFERENCES}

Arikunto Suharsimi. (2006).Prosedur penelitian, (Jakarta: PT Rineka Cipta)

Brown, Douglas and Priyandava Abeywickrma. (2010). Language assessment: Principles and classroom practice, (New York: Pearson Education)

Carol Griffiths. (2008). Lesson from good language learners, Cambridge: Cambridge University Press. 